\title{
Cyclic AMP and PKA: How can a Lot of Good Come from the Potentially Bad?
}

\author{
Editorial to: "Phosphodiesterase III Inhibition Increases cAMP Levels and Augments \\ the Infarct Size Limiting Effect of a DPP-4 Inhibitor in Mice with Type-2 Diabetes Mellitus" \\ by Y. Birnbaum et al.
}

\author{
Barbara Huisamen
}

Published online: 2 October 2012

(C) Springer Science+Business Media New York 2012

Obesity is currently classified as a pandemic and is recognized as a leading cause in the development of the metabolic syndrome, a cluster of pathophysiology that includes insulin resistance or glucose intolerance (pre-diabetes), type 2 diabetes, hypertension and atherogenic dyslipidaemia [1, 2]. According to the World Health organization (WHO), non-communicable diseases such as heart disease, stroke, cancer, chronic respiratory diseases and diabetes, are currently (updated June 2011) the leading causes of mortality in the world [3].

The role of glucagon-like peptide-1 (GLP-1) in the aetiology of insulin resistance and type 2 diabetes and as potential treatment of this debilitating disease has been extensively researched over the past 15 years. Research has led to the formulation of both long-acting GLP-1 analogues as well as dipeptidyl-peptidase-4 (DPP4) inhibitors for clinical use $[4,5]$. Direct protective effects of GLP-1 on the cardiovascular system have been demonstrated in animal models [6, 7] as well as in patients [8]. However, less information is available regarding cardio-protective effects of the DPP4 inhibitors. In addition to preventing the deactivation of endogenous GLP-1, DPP4 inhibitors also have anti-inflammatory properties and can bind adenosine deaminase, thereby elevating extracellular adenosine levels [9].

Because the receptor-mediated effects of GLP-1 may be relayed via an increase in intracellular cAMP and activation of PKA, in this issue of Cardiovascular Drugs and Therapy Birnbaum et al. hypothesize that, if they could inhibit the degradation of cAMP, they could possibly augment the

\section{B. Huisamen $(\bowtie)$}

Department of Biomedical Sciences, Division Medical Physiology,

Faculty of Medicine and Health Sciences,

University of Stellenbosch,

PO Box 19063, Tygerberg 7505, South Africa

e-mail: bh3@sun.ac.za protective effects DPP4 inhibition [10]. In this study, they made use of a phosphodiesterase-3 inhibitor, cilostazol, to elevate intracellular cAMP levels as they had previously shown that this compound could augment the infarct-sparing effect of a GLP-1 receptor agonist in mice with type 2 diabetes mellitus [11]. They therefore wished to extend their previous results using the longacting GLP-1 analogue exenetide, with a DPP4 inhibitor MK0626.

Birnbaum et al. made use of the well-known mouse model of type 2 diabetes, the $\mathrm{Db} / \mathrm{Db}$ mice, and their C57BL/6 littermates and pre-treated the animals with selected doses of MK0626 plus/minus cilostazol. They measured diverse end-points of interest, such as effects on glucose handling, cholesterol and tri-glyceride levels and antiinflammatory effects of these substances, but their main focus was on the possible cardioprotective effects as well as the mechanisms involved in such effects.

This study rendered quite a number of novel observations, such as that inhibition of phosphodiesterase-3 will elevate GLP-1 levels. This is of interest as the mechanism of GLP-1 secretion from the gut is still not fully understood. Could this be proof of the previously postulated roles of a cAMP/PKA-mediated mechanism? $[12,13]$ With regards to the utilization of substances that will enhance cAMP levels, care must however be taken because of the possibility of negative myocardial actions in the form of the development of arrhythmias [14]. The incidence of arrhythmias on reperfusion after ischaemia was not reported in the current study but was stated as an exclusion factor.

Another novel finding of this study is that the combination therapy of a DPP4 inhibitor with cilostazol will enhance the anti-inflammatory actions of either substance alone. In view of the strong link between inflammation and the 
development of myocardial pathology also in type 2 diabetes, this observation warrants further investigation.

Although both DPP4 inhibition and phosphodiesterase inhibition have previously been described to have myocardial protective abilities, it is of interest that the combination of treatments enhances the protective abilities of these drugs, resulting in a significant larger reduction in infarct size. This finding of course also has clinical implications for the development of combination therapies to reduce infarct size. It would be interesting to also study the post-treatment effects of these substances on myocardial function!

The reported results of this study on the expression of the phosphatase PTEN and the effects that this might have on several of the observed actions of the substances under investigation, is equally interesting in light of the regulatory function of PTEN on the PI3-kinase/Akt pathway, not only with its strong association with myocardial protection, but leading also to eNOS phosphorylation and CREB activation.

In total, this study adds to the current knowledge regarding the utilization of DPP4 inhibition in the treatment of type 2 diabetes and the cardiovascular pathology accompanying this disease. It has furthermore opened up the possibility of enhancing the effects of DPP4 inhibition in the form of combination therapy with cilostazol, an aspect that may also be investigated clinically.

\section{References}

1. National Cholesterol Education Program (NCEP). Expert panel on detection, evaluation and treatment of high blood cholesterol in adults. Third report of the NCEP-Adult Treatment panel III, final report. Circulation. 2002;106:3143-421.
2. Balkau B, Charles MA. Comment on the provisional report from the WHO Consultation. European Group for the Study of Insulin Resistance (EGIR). Diab Med. 1999;16:442-3.

3. Tahrani AA, Piya MK, Kennedy A, Barnett AH. Factsheet of the World Health Organization. 2011. www.who.int/mediacentre.

4. Glycaemic control in type 2 diabetes: Targets and new therapies, PharmacolTher. 2009.

5. Barnett A. DPP4 inhibitors and their potential role in the manegement of type 2 diabetes. Int J ClinPract. 2006;60:1454-70.

6. Mannucci E, Rotella CM. Future perspectives on glucagon-like peptide-1, diabetes and cardiovascular risk. NutrMetabCardiovasc Dis. 2008; 18:639-45.

7. Huisamen B, Genade S, Webster I, Lochner A. Signalling pathways activated by glucagon-like peptide-1 (7-36) amide in the heart and their role in protection against ischemia. Cardiovasc $\mathrm{J}$ of Afr. 2008;19:77-83.

8. Lonborg J, Vejlstrup N, Kelbaek H, Botker HE, Kim WY, Mathiasen $\mathrm{AB}$ et al. Exenatidereduces reperfusion injury in patients with STsegment elevation myocardial infarction. EurHeart J. 2011.

9. Lee JG, Kang DG, Yu JR, Kim Y, Kim J, Koh G, et al. Changes in adenosine deaminase activity in patients with Type 2 diabetes mellitus and effect of DPP-4 inhibitor treatment onADA activity. Diabetes Metab J. 2011;35:149-58.

10. Birnbaum Y, Castillo AC, Qian J, et al. Phosphodiesterase III inhibition increases cAMP levels and augments the infarct size limiting effects of a DDP-4 inhibitor in mice with type- 2 diabetes mellitus. Cardiovasc Drugs Ther 2012;26 this issue.

11. Birnbaum Y, Castillo AC, Ling S, Bajaj M, Perez-Polo JR, Ye Y. Amplification of the myocardial infarct size limiting effects of exenatide with cilostazol, a phosphodiesterase III inhibitor. J Am CollCardiol. 2012;59:A110.

12. Drucker DJ, Brubaker PL. Proglucagon gene expression is regulated by a cyclic AMP-dependent pathway in rat intestine. ProcNatlAcadSci U S. 1989;A86:3953-7.

13. Drucker DJ, Jin T, Asa SL, Young TA, Brubaker PL. Activation of proglucagon gene transcription by protein kinase-A in a novel mouse enteroendocrine cell line. Mol Endocrinol. 1994;8:1646-55.

14. Lubbe WF, Podzuweit T, Opie LH. Potential arrhythmogenicrole of cyclic adenosine monophosphate (AMP) andcytosolic calcium overload: implications for prophylactic effectsof beta-blockers in myocardial infarction and proarrhythmiceffects of phosphodiesterase inhibitors. J Am CollCardiol. 1992;19:1622-33. 